\title{
Football and exchange rates: Empirical support for behavioral economics
}

Article in Psychological Reports · November 2007

DOI: 10.2466/PR0.101.6.643-654 · Source: PubMed

CITATIONS

8

3 authors, including:

M. Hakan Berument

Bilkent University

142 PUBLICATIONS 1,609 CITATIONS

SEE PROFILE
Burak Dogan

central bank of TRNC

10 PUBLICATIONS 22 CITATIONS

SEE PROFILE

Some of the authors of this publication are also working on these related projects: 


\section{FOOTBALL AND EXCHANGE RATES: EMPIRICAL SUPPORT FOR BEHAVIORAL ECONOMICS}

\section{GULIN EKER}

Department of Turkish Language and Literature Hacettepe University

\section{HAKAN BERUMENT}

Department of Economic Bilkent University

BURAK DOGAN

Undersecretariat of Turkish Treasury

Summary,-Recently, economic theory has been expanded to incorporate emotions, which have been assumed to play an important role in financial decisions. The present study illustrates this by showing a connection between the sports performance of popular national football teams (Besiktas, Fenerbahce, and Galatasaray) and performance of the Turkish economy. Specifically, a significant positive association was found between the success of three majot professional Turkish football teams and the exchange rate of the Turkish lira against the U.S. dollar. The effect of the football success of several Turkish football teams on the exchange rate of the Turkish lira was examined using the simultancous multiple regression model with predictor measures of wins, losses, and ties for different combinations of teams to predict the depreciation rate of the Turkish lira between the years 1987 and 2003. Wins by Turkish football teams against forcign (non-Turkish) tivals increased with exchange rate depreciation of the Turkish lira against the U.S. dollar.

Emotional factors contributed an important role in behavioral economics and finance (Loewenstein, 2000; Romer, 2000) as choices and strategies of economic agents depend on their emotional states (see Stracca, 2004, and the references cited therein for relevant literature).

The number of studies assessing the significance of emotional factors in decision-making has increased recently. Now there is a world-wide literature analyzing the effects of football, called soccer in the USA, on various macro series. For example, Ashton, Gerrard, and Hudson (2003) noted a statistically significant positive relation between performance of England's national football team and the price movement of the shares in the London Stock Exchange's FTSE100 index, which represents the share prices of the 100 largest companies traded in the London Stock Exchange. Berument, Ceylan, and Gozpinar (2006) and Edmans, García, and Norli (2007) also provided evidence that the success of football teams affects the stock market. The former reported that Turkish teams' wins against foreign rivals were associated

'Address correspondence to Hakan Berument, Department of Economics, Bilkent University, 06800. Ankara, Turkey or e-mail (berument@bilkent.edu.tr). We thank Anita Akkas and the anonymous referees for their valuable comments. 
with increased returns in the Istanbul Stock Exchange, whereas the latter work, using cross-sectional data from 42 countries, showed losses in international football games resulted in statistically significantly lower returns in stock markets, but they did not find similar evidence for wins.

Pollard (2002) provided evidence of a relationship between the World Cup successes of selected countries and their growth performance by observing the real GDP growth of the World Cup winner countries in the winning year. Berument and Yucel (2005) argued that, since success of football teams could be interpreted as a proxy for the economic agents' mood and self-esteem, higher production due to better social behavior and more efficient decision-making by agents should be observed. They provided empirical evidence that wins against foreign rivals were associated with increases in Turkish Industrial Production Index growth. This paper assesses only the direct effects of football success on exchange rates. Even if there might be an indirect effect of football successes on the exchange rate through growth and stock markets, since daily data were used, assessing this indirect effect was not feasible.

To be more specific, two types of questions may be asked: (1) whether each type of result affects the exchange rate (if the win, tie, and loss of each game affects the depreciation), and (2) whether the score of each game affects the depreciation in the same way since each team's supporters have different socioeconomic backgrounds. Answers to these questions were sought using transfer function analysis similar to procedures of Berument and Yucel (2005) and Berument, Ceylan, and Gozpinar (2006).

There are various reasons for looking at the effect of football success on the exchange rates of the Turkish lira. Firstly, the exchange rate is the most easily accessible financial variable in Turkey as in most emerging economies. Secondly, the volatility of the exchange rate for most emerging markets is high; therefore, Type 2 error-not rejecting the null when it is false-is lower (see Neter, Wasserman, \& Kutner, 1985, p. 71; Berument, Akdi, \& Atakan, 2005). Thirdly, the foreign exchange rate might conceivably be used as a proxy for saving behavior in most of the economies that do not have well-functioning, stable financial markets. For example, Conway (1995) and others cited therein argued that savings are made in foreign currency in economies with high and volatile inflation. For example, with high inflation, the pricing mechanism will not work properly. Indeed, the nominal interest rates did not match the increase in inflation for Belarus, Georgia, Kazakhstan, and the Ukraine. This makes the real return on national currency nominated savings negative. Therefore, savings were usually held in foreign currency to avoid deterioration of private wealth. The Central Bank of The Republic of Turkey $(1999,2007)$ argued the same for Turkey. Thus, higher savings demands increase the demand for foreign currency and an increase in foreign 
currency demands increase its price, so the exchange rate increases (depreciation).

Social psychology literature suggests that supporters are affected by the success of their team, which in turn affects their decision-making (see, for example, Kimble \& Cooper, 1992; Parkinson, Totterdell, Briner, \& Reynolds, 1996; and Ibarra, 1999). Tolman (1943) and Ibarra (1999) argued that following a win by their team, supporters feel more confident about themselves and their decision-making. Hirt, et al. (Hirt, Zillmann, Erickson, \& Kennedy, 1992) noted that after a win supporters overestimate their own performance. As a result of this, like Ashton, et al. (2003), economic agents demand more assets and the demand for foreign exchange increases in nonperfectly functioning financial markets. In an emerging market such as Turkey, this kind of a behavioral choice increases the value of the foreign currency (U.S. dollar) in the domestic currency (Turkish lira), so depreciation occurs (one may look at Stracca, 2004, and Lester, Yang, \& Spinella, 2006, for reasons concerning increased demand for assets under various emotional and visceral factors.)

Usually, when looking at the effects of wins on foreign exchange, it is important that only the effect of scores for games played against foreign rivals are taken into consideration. Two basic reasons can be cited for this. Firstly, a win against a domestic rival means a loss for another domestic team, so the effect of a win of one team may be canceled out by the effect of another team's loss. Secondly, as Berument and Yucel (2005) argued, wins against foreign rivals may boost self-esteem even more because both national pride and being a supporter of a domestic team are involved. In the next section the models used to estimate the behavior of the exchange rate are presented.

MODEI.

To assess the effects of the foreign games by Turkish teams on the depreciation rate, one of the most popular time series methods, transfer function analysis, was adopted. This method is a form of multiple linear regression analysis used to assess the role of a set of exogenous variables in explaining the behavior of a dependent variable not predicted by the lagged dependent variables when all the variables enter the specification simultaneously. To be specific, it is assumed that the dependent variable is explained by its own lag values; and if a set of exogenous variables has explanatory power after considering the dynamics of the dependent variable, this set of exogenous variables is said to have explanatory power for the dependent variable (see Enders, 2004, pp. 247-261; Berument \& Yucel, 2005, for details). Thus first the following multiple regression model was proposed: 


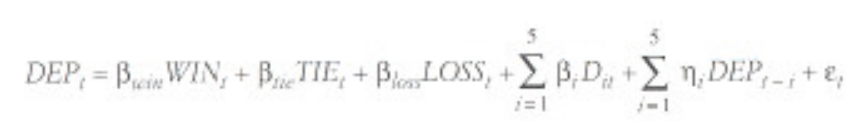

where $D E P$, stands for the daily exchange rate depreciation for the Turkish lira in terms of U.S. dollars, and the subscript $t$ is used for its time period. Depreciation is defined as

$$
D e p_{f}=\left(\frac{U S D_{t}-U S D_{t-1}}{U S D_{i-1}}\right) \times 10000
$$

where USD, is the Turkish lira value of the U.S. dollar at Day $t . D E P_{t-1}$, $D E P_{t-2} \ldots D E P_{t-5}$ are the $1,2, \ldots 5$ daily lag values of the depreciation rates. $W I N_{t}$ is the number of wins a team has against a foreign rival in the Champions League. Similarly, TIE $E_{t}$ and LOSS are the variables for the number of ties and losses at each given Day $t$ against foreign rivals in the Champions League. Note that WIN, TIE, and $L O S S_{t}$ variables were used on the success of football teams as an observation for the next business day because all the games were played after the operating hours of financial markets. Variables $D_{1 t}$ to $D_{5 t}$ are the dummy variables for each day of the week, which are set to address the day of the week effect for Monday through Friday. For example, $D_{l t}$ takes the value of 1 for Mondays, and 0 otherwise; $D_{2 t}$ takes the value of 1 for Tuesdays, and 0 otherwise, etc. There are two reasons for including the day of the week effect. One is that it accounts for a possible systematic variation in the depreciation rate. Aydogan and Booth (2003) argued that, given the different liquidity requirements of firms, demands for foreign exchange (and thus the depreciation rates) will be different. They observed that Tuesdays will have higher depreciation rates than Fridays. Moreover, Tuesdays and Wednesdays are the official match days of the Champions League. If one excluded the day of the week effect, one might attribute higher or lower returns on the next business day (Wednesdays and Thursdays) to success in football rather than the day of the week effect.

The data for daily depreciation were gathered from a daily newspaper. ${ }^{2}$ For the success of football, the scores of the top three teams in Turkey, Besiktas, Fenerbahce, and Galatasaray, were observed. These three teams are the biggest in terms of their number of supporters. These teams have supporters all over Turkey, not just concentrated in one or two geographic regions. Thus, the wins of these teams are likely to affect Turkey all over compared to a regional team's wins. Moreover, most people associate self with one of these teams; a supporter of a local team is also likely to associate self with one of these teams. These teams are also considered to be the most

${ }^{2}$ Hurriyet (http://www.hurriyetim.com). 
successful. Since the establishment of the Turkish Professional Football League in 1959, only four teams have been able to win the national championship: Besiktas, Fenerbahce, Galatasaray, and Trabzonspor. Trabzonspor, considered a local team, won its last championship in the 1983-84 season.

As a separate exercise, the relationship between exchange rate depreciation and the wins of other Turkish football teams (besides Besiktas, Fenerbahce, and Galatasaray) against foreign rivals was assessed. Evidence was not statistically significant (not reported). These were parallel to the evidence on the industrial production (Berument, Inamlik, \& Yucel, 2003) and on stock market returns (Berument, Ceylan, \& Eker, 2007).

The data for Fenerbahce's and Galatasaray's scores were gathered from Tuncay (2001) and Tanrikulu (2002), respectively. The data for these two teams, as well as for Besiktas, were updated from a daily Turkish newspaper's database.

\section{Results}

The nonstandardized estimated coefficients and the Newly-West robust standard errors obtained from Eq. 1 along with the standardized beta are reported in the first three columns of Table 1 (labelled Model 1) for the daily data of the period between $26 / 10 / 1987$ and $15 / 10 / 2003$ with a total of 4,169 observations. The beginning of the sample, the late $80 \mathrm{~s}$, overlaps with the rise of the financial liberalization efforts of Turkey when individuals were allowed to buy foreign exchange easily from Foreign Exchange Bureaus for savings purposes; thus, foreign exchange rates could respond to emotional factors. The end of the sample corresponds to the stabilization of the economy, which encouraged the use of Turkish lira-denominated assets for savings rather than foreign exchange. During this period, Besiktas had 11 wins, 8 ties, and 13 losses; Fenerbahce had 4 wins, 3 ties, and 13 losses; and Galatasaray had 35 wins, 25 ties, and 35 losses; thus, a total of 50 wins, 36 ties, and 61 losses against foreign rivals. The estimated coefficient for wins was positive and statistically significant at the $10 \%$ level (the selected level of significance is $10 \%$ unless otherwise indicated) and $1.15 \%$ of the variation of the depreciation was accounted for by the WINs (percentage variations not reported in the table to save space). This supports the hypothesis that the depreciation rate increases with wins in football. Since the Efficient Market Hypothesis suggests that the behavior of foreign exchange rate depreciation is not predictable, no variable should explain the behavior of the exchange rate (see Kan \& Andreosso-O'Callaghan, 2007, for details). Thus, the finding that WINs explained $1.15 \%$ of the variation for the exchange rate was indeed high. On the other hand, the matches ending in a tie or a loss were

http://www.hurriyetim.com. 
not statistically significant and had negative coefficients. The effect associated with losses was greater than that for ties in absolute values. This is parallel to work by Hewitt and Jackson (1986), who argued that attributions were different after winning than after losing. It is important to note that the day of the week effect on the depreciation rate has to be considered in the estimation process. In Model 1 of Table 1, it can be observed that the coefficient of the Tuesday dummy was positive and statistically significant (explaining $0.41 \%$ of the variation in the depreciation rate). In contrast, the coefficient of the Monday dummy was negative and statistically significant (around $0.52 \%$ of the variation was explained by the Monday effect). Among the remaining weekdays, only the Friday dummy had a negative coefficient $(0.47 \%$ of the variation was explained by Friday $)$, while all three coefficients were below the $10 \%$ statistical significance chosen. These results were consistent with Aydogan and Booth (2003).

Considering that the result of a match can only be a win, tie, or loss, there may be a certain amount of collinearity when these three variables are entered together in the model. To account for this effect, these variables individually were entered.

$$
D E P_{i}=\alpha_{1} \operatorname{Ressl}_{i}+\sum_{i=1}^{5} \beta_{j} D_{i t}+\sum_{i=1}^{5} \eta_{i} D E P_{t-j}+\varepsilon_{i}
$$

where Result $t_{s}$ is either a win or a tie or a loss. The estimation output obtained when WIN is the only match result used can be seen in Model 2 of Table 1 . The effect of the wins by the three teams was again positive and statistically significant $(1.17 \%$ of the variation of the depreciation rate was explained). Moreover, the day of the week dummies suggested that (according to Model 2 of Table 1), Tuesday, Wednesday, and Thursday had positive and the rest of the days had negative effects on exchange rate depreciation. While only Monday and Tuesday were statistically significant, Monday and Tuesday variables explained $0.52 \%$ and $0.41 \%$ of the variation in the depreciation rates, respectively. Models 3 and 4 present the estimation output of Eq. 2 when "Result" is replaced by TIE and LOSS, respectively. As can be seen in Model 3, the depreciation rate for the Turkish lira in U.S. dollars increased due to a tie, but the coefficient was not statistically significant. This result might indicate that Turkish citizens react positively to not being beaten by a foreign team. However, as Model 4 presents, the total losses of the three teams were not significantly related to the depreciation of the exchange rate. Models 3 and 4 of Table 1 also show that the Tuesday, Wednesday, and Thursday dummies positively predicted the exchange rate depreciation with statistically significant coefficients for Tuesday and Thursday (Tuesday explained $0.44 \%$ of the depreciation for both models, and Thursday explained $0.27 \%$ and $0.25 \%$ of the variation for Models 3 and 4 , 
TABLE 1

Exchange Rate Depreciation Due to Total. Wins, Ties, and Losses ay Teams and Day of Week

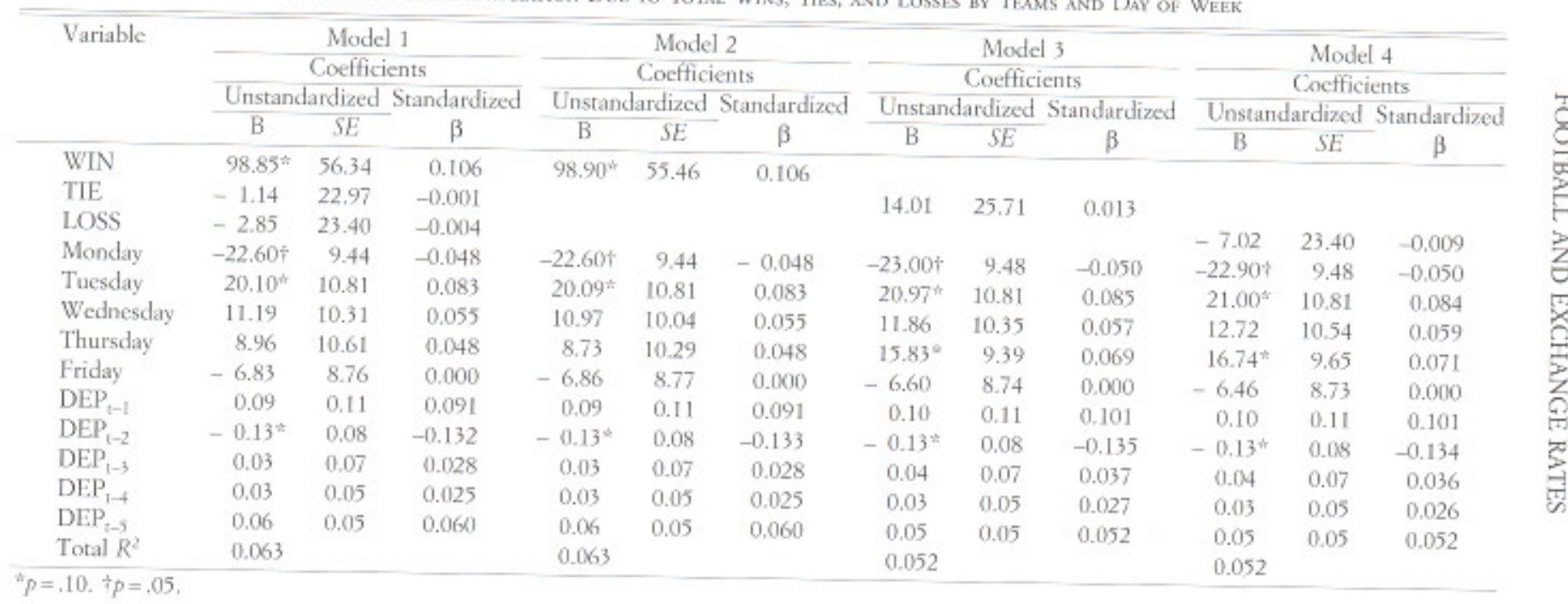


respectively). The Monday and Friday dummies, on the other hand, were negative for Models 3 and 4, and only the Monday dummy was significant in both of the tables $(0.53 \%$ of the depreciation variation was explained by Mondays).

Berument, et al. (2003) noted that each team has different types of supporters coming from different socioeconomic backgrounds; thus, they could respond differently to the scores of the matches. For this reason the investigation was carried one step further and tested for the effects of the individual wins achieved by the three teams. The following model was used for the estimation process

$$
D E P_{i}=\alpha_{1} B W_{i}+\alpha_{2} F W_{i}+\alpha_{3} G W_{t}+\sum_{j=1}^{5} \beta_{i} D_{i j}+\sum_{j=1}^{5} \eta_{j} D E P_{i-i}+\varepsilon_{j}
$$

where $B W_{t}, F W_{t}$, and $G W$, represent the Champions League wins achieved by Besiktas, Fenerbahce, and Galatasaray, respectively. According to the estimates output of Eq. 3, which is presented in Model 5 in Table 2, each team's wins were related positively to exchange rate depreciation. Moreover, the coefficients of $F W_{t}$ and $G W$, were far higher than the coefficient of $B W$ (136.48 for Fenerbahce and 111.22 for Galatasaray vs 5.27 for Besiktas) and were statistically significant. Almost none of the depreciation variation was explained by Besiktas's wins, $0.16 \%$ of the variation was explained by Fenerbahce's wins, and almost $0.12 \%$ of the variation was explained by Galatasaray's wins. This result seems reasonable since Fenerbahce and Galatasaray have supporters whose socioeconomic status is higher than that of the Besiktas supporters. They increased their savings after a win; thus, currency depreciated more after wins of Fenerbahce and Galatasaray (Ögüut-Eker, 2006, studied the slogans that supporters used during the football matches and classified the socioeconomic status of each team's supporters). Furthermore, the day of the week effect was present for Monday (negative) and Tuesday (positive), with statistically significant coefficients and explained $0.52 \%$ and $0.40 \%$ of the variation of the depreciation rate, respectively.

The matches ending in a tie or loss were also included in the model. Considering the tie scores as the explanatory variable, the variables $B W$, $F W$, and GW of Eq. 3 were replaced with BT, FT, and GT (ties achieved by Besiktas, Fenerbahce, and Galatasaray), respectively, as follows:

$$
D E P_{i}=\alpha_{1} B T_{i}+\alpha_{2} F T_{i}+\alpha_{3} G T_{i}+\sum_{i=1}^{5} \beta_{i} D_{j t}+\sum_{i=1}^{5} \eta_{i} D E P_{i-i}+\varepsilon_{i}
$$

The estimation output of Eq. 4 is presented in Model 6. A tie score achieved by Fenerbahce was positively associated with the depreciation rate, and the coefficient was statistically significant, as well as being higher (97.79) than 
TABLE 2

Exchange Rate Deprecition by Individual. Wins. Ties, and losses of Each of Thref Teams and Day of Whek

\begin{tabular}{|c|c|c|c|c|c|c|c|c|c|}
\hline \multirow[t]{3}{*}{ Variable } & \multicolumn{3}{|c|}{$\begin{array}{c}\text { Model 5: Wins } \\
\text { Coefficients }\end{array}$} & \multirow{2}{*}{\multicolumn{3}{|c|}{$\begin{array}{l}\text { Model 6: Ties } \\
\text { Coefficients } \\
\end{array}$}} & \multirow{2}{*}{\multicolumn{3}{|c|}{$\begin{array}{l}\text { Model 7: Losses } \\
\text { Coefficients }\end{array}$}} \\
\hline & \multicolumn{2}{|c|}{ Unstandardized } & \multirow{2}{*}{$\begin{array}{c}\text { Standardized } \\
\beta\end{array}$} & \multicolumn{2}{|c|}{ Unstandardized } & & Unstandardized & & \multirow{2}{*}{$\begin{array}{l}\text { Standardized } \\
\beta\end{array}$} \\
\hline & B & $S E$ & & B & $S E$ & $\begin{array}{c}\text { Standardized } \\
\beta\end{array}$ & B & $S E$ & \\
\hline Besiktas & 5.27 & 12.31 & 0.002 & -11.12 & 12.04 & -0.003 & 19.80 & 12.04 & 0.010 \\
\hline Fenerbahce & $136.48 \dagger$ & 20.03 & 0.038 & 97.794 & 13.51 & 0.027 & -59.71 & 13.51 & -0.047 \\
\hline Galatasaray & $111.22^{*}$ & 67.47 & 0.107 & 7.54 & 29.69 & 0.006 & 23.35 & 29.69 & 0.023 \\
\hline Monday & $-22.66 \dagger$ & 9.43 & -0.049 & $-22.80 \dagger$ & 9.54 & -0.050 & $-23.11 \dagger$ & 9.54 & -0.050 \\
\hline Tuesday & $19,90^{*}$ & 10.81 & 0.082 & $20.99^{*}$ & 10.81 & 0.084 & $21.08^{*}$ & 10.81 & 0.085 \\
\hline Wednesday & 10,77 & 10.00 & 0.054 & 12.04 & 10.37 & 0.057 & 13.56 & 10.37 & 0,062 \\
\hline Thursday & 9.11 & 10.21 & 0.049 & 15.44 & 9.41 & 0.067 & $16.33^{\circ}$ & 9.41 & 0.071 \\
\hline Friday & -6.86 & 8.78 & 0.000 & -6.55 & 8.75 & 0.000 & -6.79 & 8.75 & 0.000 \\
\hline $\mathrm{DEP}_{1-1}$ & 0.09 & 0.11 & 0.090 & 0.10 & 0.11 & 0.100 & 0.10 & 0.11 & 0.103 \\
\hline DEP $_{t-2}$ & $-0.13^{=}$ & 0.08 & -0.132 & $-0.14^{4}$ & 0.08 & -0.135 & -0.13 & 0.08 & -0.131 \\
\hline $\operatorname{DEP}_{t-3}$ & 0.03 & 0.07 & 0.028 & 0.04 & 0.07 & 0.036 & 0.04 & 0.07 & 0.037 \\
\hline$D_{E-4}$ & 0.03 & 0.05 & 0.028 & 0.03 & 0.05 & 0.026 & 0.03 & 0.05 & 0.026 \\
\hline $\mathrm{DEP}_{\mathrm{t}-5}$ & 0.06 & 0.05 & 0.060 & 0.05 & 0.05 & 0.052 & 0.05 & 0.05 & 0.051 \\
\hline Total $R^{2}(\%)$ & 6.5 & & & 5.3 & & & 5.5 & & \\
\hline
\end{tabular}


those for the other two teams $(0.08 \%$ of the variation of the depreciation was explained by the Fenerbahce's ties).

To use the lost matches of each team as the explanatory variable the variables $B W, F W$, and $G W$ of Eq. 3 were replaced with $B L, F L$, and $G L$ (losses experienced by Besiktas, Fenerbahce, and Galatasaray, respectively) as follows:

$$
D E P_{i}=\alpha_{1} B L_{i}+\alpha_{2} F L_{i}+\alpha_{3} G L_{i}+\sum_{i=1}^{5} \beta_{i} D_{i j}+\sum_{i=1}^{5} \eta_{i} D E P_{i-i}+\varepsilon_{i} .
$$

The estimates for Eq. 5 are presented in Model 7 of Table 2. There were no statistically significant relationships between depreciation and the losses of the three teams. Moreover, the estimates of the day of the week effect for each of the daily dummies were robust.

As mentioned before, the efficient market hypothesis suggests that exchange rate depreciation should not be predictable; $R^{2}$ should be equal to zero. Thus, an $R^{2}$ calculation of 5 to $6 \%$ is indeed high. The $F$ ratios for the overall significance of the equation parameters is also high. Thus, we reject the null hypothesis that the coefficients of all parameters of the equation are zero for each specification considered here (not reported). This further supports the validity of the models.

\section{CAVEATS}

Also estimated was the model for different samples and different types of games. When data were extended to 2004 and 2005, the basic results of the paper were robust. Moreover, when the model for each of the years between 1987 and 2005 was estimated, the estimates for the sample years of 2004 and 2005 were weak. This supports Conway's proposition that as long as the economy is considered vulnerable (or volatile), foreign currency is used for saving purposes.

Turkish teams played in UEFA Cup games (before 1998-99 season UEFA Cup games and Cup Winners Cup games are considered separately) as well as Champions League Cup games. Games played in Champions League are more prestigious and associated with higher monetary rewards (sce Berument, Ince, \& Yucel, 2005, for details). We made estimations by taking both types of games into consideration. Evidence was weak.

We chose the most successful (in terms of number of wins in league championships) and biggest (in terms of its supporters) three teams that have supporters all over the nation. The other tearns do not have supporters all over Turkey and do not have as many supporters. Thus, one is persuaded there is no selection bias. As a separate exercise, the wins of other teams were also included besides these three against foreign rivals but the evidence was weak. 


\section{Discussion}

The performance of the three Turkish football teams in the Champions League matches was statistically significantly related to Turkish exchange rate depreciation. The findings indicated that the total wins attained by the Turkish teams positively and significantly affected the exchange rate, while the results for total losses and total ties did not affect the exchange rate sig. nificantly. The findings also indicated that exchange rates were significantly higher on Tuesdays and lower on Mondays compared to the other weekdays. The findings for football scores were even stronger when the match results were entered into the model individually as wins, ties, and losses. Also tested was whether the effects of football wins are different for each team, perhaps due to the different socioeconomic backgrounds of each team's supporters. This effect was highest for wins by Fenerbahce and lowest for wins by Besiktas.

The findings can be explained by the influence of behavioral economics on finance. Football is a sport followed closely by a very large percentage of the population, so it is conceivable that it would have general effects on social and individual psychology, which in turn could influence general economic behavior. Emotional factors, such as enthusiasm, could extend to individuals' choices and strategies, following wins against non-Turkish teams. These choices may depart from cognitive decisions which might have been made differently had the person been angry or had a negative feeling after a loss to a non-Turkish team. In the end, the emotional effects on choices need not be rational in the classical manner and most probably occur due to people identifying "self" with a football team or a supporters group.

\section{REFERENCES}

Asurton, J. K., Gerrard, B., \& Hudson, R. (2003) Economic impact of national sporting suc. cess: evidence from the London Stock Exchange. Applied Economic Letters, 10, 783-785.

Ardogan, K., \& Booth, G. G. (2003) Calendar anomalies in Turkish Foreign Exchange markets. Applied Financial Economio, 13, 353-360.

Bentumfint, H., Akd, Y., \& Atakan, C. (2005) An empirical analysis of Istanbul Stock Ex. change sub-indexes. Studies in Nonlinear Dynamios and Econometrios, 9 (Article 5).

Berument, H., Cerlan, N. B., \& Eker, E. (2007) Football, stock returns and fanaticism: evidence from Turkey. Unpublished manuscript, Bilkent Univer.

Berument, H., Ceylas, N. B., \& Gozpinar, E. (2006) Performance in soccer and stock market: evidence from Turkey. Social Science Journal, 43, 695-699.

Berument, H., Inamlik, A., \& Yucer, M. E. (2003) [The effects of football on productivity. Iktisat, Isletme ve Finans, 212, 51-62. [in Turkish]

Bertument, H., InCE, O., \& YuCE, E. (2006) Success in soccer and economic performance evidence from Besiktas-Turkey. RISEC, 53, 260-274.

Berument, H., \& YUcel, M. E. (2005) Long live Fenerbahce: production boosting effect of football in Turkey. Journal of Economic Psycbology, 26, 842-861.

Central Bank of The Republic of Turkex. (1999) Ammal report. Ankara, Turkey: Author.

Central. Bank of The Repubuc of Turkey. (2007) Annual report. Ankara, Turkey: Author.

Conway, P. (1995) Saving in transition economies. World Bank Policy Research Working Paper, 1509 . 
Edmans, A., Garcis, D., \& Norl, Ø. (2007) Sports sentiment and stock returns. Journd of Findance, 62, 1967-1998.

ENDERs, W, \{2004\} Applied econometric time series. (2nd ed.) New York: Wilcy.

HewrtT, J., \& JAcksos, S. (1986) Differential attributions for win-loss in competitive tennis. Perceptual and Motor Skills, 63, 970 .

Hirt, E. R. Zimmins, D. Erickson, G. A. \& Kennedr, C. (1992) Cost and benefits of alle giance: changes in fans' self-ascribed competencies after team victory versus defeat. Journal of Peronality and Social Psychology, 63, 724-738.

IRARRA, H. \{1999) Provisional selves: experimenting with image and identity in professional adaptation. Administrative Science Quavterly, 44, 764-791.

Kan, D., \& Andreosso-O'C.Llaghun. B. (2007) Examination of the efficient market hypothesis-the case of post-crisis Asia Pacific countries. Joumal of Asian Economio, 18, 294. 313

Kimble, C. E., \& Coopre, B. P. (1992) Association and disassociation by football fans. Perceptual and Motor Skifls, 75, 303-309.

L.este.r, D., YANG, B. J., \& Sprnell., M. (2006) Depression, anxiety, and personal finance be havior: implications for the classical economic conception of humans as rational decisionmakers. Psychological Reponts, 99, 833-834.

Loewenstein, G. F. (2000) Emotions in economic theory and economic behavior. American Ecotromic Reviete, 65, 426-432.

Neter, I., Wasserman, W., \& Kutner, M. H. (1985) Applied linear statistical models. (2nd ed.) Homewood, IL; Richard D. Irwin.

ÖG0T-EkFr, G. (2006) The irresistible attractiveness of football and a magnetized supporter portrait. Unpublished manuscript, Hacettepe Univer. [in Turkish]

Parkinson, B., Totterneli, P., Briner, R. B., \& Reynolds, S. (1996) Changing mood's: the psydology of mood and morad regulation. London: Longman.

Pol.tard, P. S. (2002) Grooowwwth! International Economic Trends. (Annual Edition)

Romer. P. M. (2000) Thinking and feeling. American Economic Revietw Papers and Proceedings. $90,439-443$.

Straccs, L. (2004) Behavioral finance and asset prices: where do we stand? Jotrnal of Eco. nomic Psyobology, 25, 373-405.

Tanaukuit, A. (2002) [History of Fenerbabee with its legends, beros and nismbers]. Istanbul: Yape Kredi Cultural Press. [in Turkish]

Tolman, E. C. (1943) Identification and post-war world. Toumal of Abrormal and Social Psy. chology, 38, 141-148.

Tuncay, B. (2001) [The bistory of Galotasaray: with European victories and anforgettable stars]. Istanbul: Yap1 Kredi Cultural Press, [in Turkish] 